\title{
Collections Redux: The Public Library as a Place of Community Borrowing
}

\author{
Jonas Söderholm and Jan Nolin
}

\begin{abstract}
This article presents an overview of the Western public library's development into its present form(s) and its shift to the prevailing social perspective. This leads to a discussion of "digital and point-oh libraries" as one of two major strands and "social space and place" as the other. Our main critique is that this development has caused an unfortunate downplay of societal perspectives in favor of a focus on social issues. Another side effect is a growing lack of attention to the potential of physical, on-site collections. By proposing a specific counterexample, we discuss library collections as a community concern and as a step toward bridging the social-societal gap. The potential of a redefined on-site collection is set against the backdrop of public libraries offering nontraditional collections, such as tool-lending libraries.
\end{abstract}

A

predominant school of thought in LIS today is what can be framed as the social, in which the library is a locus and an enabler of social processes in the interpersonal sense. This marks a transition in which touchstones such as popular education have given room to other concepts, including communication, sociological influences, and user studies. It is a turn in how library issues are framed: from a societal perspective to a social perspective, from the building of society to the building of relations. There are two major strands currently at the forefront. They overlap in some respects but are also quite distinct. The first strand is concerned with the digital extension of libraries and includes issues spanning from backend collection management to front-end e-reading and social media. Generally the research focuses on either the "digital library" (Borgman 1999; Candela, Castelli, and Pagano 2011) or on the popular "point-oh" perspectives (Carlsson 2012; Kwanya, Stilwell, and Underwood 2013). The second strand focuses on the public library as a worldly located place of social activity. Issues concern the library as a meeting place or as an extension of other environments, such as home or work (Audunson 2005; Johannesson 2009; Skot-Hansen, Rasmussen, and Jochumsen 2013).

In both cases, whether enabled by new media or by the idea of a common public space, social dimensions are in focus. The social can also be framed as an emphasis on developing (infra)structure rather than content by focusing on modes of provision, outreach strategies, accessibility, and the architecture of facilities and information.

Library Quarterly: Information, Community, Policy, vol. 85, no. 3, pp. 244-260. (C) 2015 by The University of Chicago. All rights reserved. $0024-2519 / 2015 / 8503-0002 \$ 10.00$

244 
Recently there has been a renewed interest in community engagement (Goulding 2009; Scott 2011; Sung, Hepworth, and Ragsdell 2013). This article is an effort to invigorate a "classical" societal perspective using the notion of community as a merger of societal and social approaches. Among the things we find wanting in discussions emphasizing the social is inquiry into the potential of the public library's already well-established traditional (infra)structure in its most concrete form: the on-site physical collection. This in turn provides immediate connections to one of the aforementioned strands - the library as place. Thus, the research aim of this conceptual article is twofold: first, to propose an extension of the social perspective of library development by a renewed attention to societal aspects and, second, to discuss the potential of merging the ideas of place, collection, and community to bridge the social-societal gap.

This article is structured in three sections: the development of public libraries into the predominant social perspective, revitalization of the societal perspective, and a concluding discussion.

\section{The Social Turn}

\section{Post-Fordist Production and the Public Library}

Until the nineteenth century, libraries were irrelevant to the general public. They had developed from carefully administrated repositories of recorded knowledge, without any obvious outward purpose, to a university concern spawned during the Enlightenment (Harris 1999; Lerner 2009). Public libraries in the sense familiar to us were only realized in the late nineteenth to early twentieth century as part of the social reform movements rising in the United Kingdom and the United States. Like other community institutions such as settlement houses, ${ }^{1}$ public libraries were expressly targeted at the underserved citizenry. The general idea of the library had shifted from a stockpile of the records of humankind to an institution for the general public. Early twentieth-century public libraries were concerned with literacy and oriented toward education, initially of the adult population but increasingly including children. This social mission for the underserved is today mostly diminished as the public library has shifted its status to being a cultural concern of the middle classes, and "only in service to children does the old missionary zeal linger with any real success” (Lerner 2009, 125). During the course of the twentieth century, public libraries largely left the context of community-based, targeted social support, whereas the legacy of settlement houses can still be found in today's neighborhood centers (Yan and Sin 2011).

The transformation of the public library in the Western world is linked to a shift in the production and distribution of goods. Domestic material production has gradually given way

1. Settlement houses were establishments of the settlement movement in the United Kingdom and the United States in the late 1800 s and early 1900s. They were efforts to strengthen communities through negation of social class gaps, mainly by supporting immigrants. The local settlement house both provided day-to-day services for individuals in need and engaged in long-term reform work (Koerin 2003; Yan and Sin 2011). 
to the immaterial production of services, a transformation still under way. Generally the era that we have moved from is usually framed as one of two -isms, industrialism or Fordism. Accordingly, the present is described as either postindustrialism or post-Fordism. The term "postindustrialism" is usually attributed to Daniel Bell (1973). However, Bell's account still builds on production-centric metaphors of industry. Somewhat bluntly, the telling difference between postindustrialism and industrialism is that new types of products (information, made up of data) are manufactured by new types of machinery (computers, operated by information professionals) (Harris, Hannah, and Harris 1998). The Fordist, or Fordist-Keynesian, era depicts a later and narrower time frame, peaking after World War II. The defining tenet was mass production for mass consumption, which at the time was a decidedly positive concept of freedom and empowerment for both worker and consumer. Today's largely negative connotation of the "mass" prefix follows the shift to post-Fordism. It is a structure of ideological change that is larger than merely renewed modes of production. The single strongest factor that affects or at least signifies this shift is globalization (Webster 2006). Globalization can be described as the general direction of many movements dealing with interdependence and exchange across nations: economic, social, cultural. To frame current Western society as a post-Fordist era is to emphasize how we do things rather than what we do. By this token, the development of public libraries is defined by profound structural and professional change and not merely by shifting focus from paper to information.

The organizing principle of the public library in the later twentieth century is evident in this post-Fordist transformation. Earlier libraries placed an emphasis on large buildings holding extensive collections of books. This offers some analogy to production-line industry that emphasized large storage facilities of well-indexed and well-categorized items. This all changed with "just in time" production ideals, which also affected public library practices. The book became increasingly mobile, with one book serving several libraries. Book buses and interlibrary lending reduced the place dependency of a given item, making collections mobile. Quite often the main library was cut down in size, requiring smaller facilities serving different distinct parts of the municipality. A recent symptom of this change is collection development based on user requests, that is, patron-driven acquisitions (Nixon, Freeman, and Ward 2010). Moving the book and the library closer to the user is obviously in tandem with the development of online services. The globalization is evident: increasing connectivity and access and the librarian's newfound role as the information professional who supports patrons in tapping into all of recorded human knowledge (Harris et al. 1998).

The public library gained authority and status by becoming a prime institution in areas considered central to society. Contemporary libraries are about information, a notion that is strongly evident in authoritative declarations such as the 2020 Vision of the British Library Board (2010) and the Bill of Rights of the American Library Association (1996). At the same time, information-based activities have enjoyed considerable growth across all sectors of society. This has put pressure on libraries to function in horizontal competition with the markets (Harris, 
Hannah, and Harris 1998; Ross and Sennyey 2008). One effect of this development is budget cuts stemming from political visions of a self-regulating, consumer-driven "information and cultures" sphere in which the public libraries of old would supply more than is popularly demanded. Notions of the oversized library and capitalist fears of unfair competition have arguably led to today's decrease in virtually all library service parameters: branches, staffing, hours, and stock. On a more qualitative note, it could also be argued that the public library has been effectively reduced to a passive information resource, serving customers. This role may indeed be politically framed as an honorable and essential function in the alleged "information society" or "digital age." It could also be seen as the squelching of the public library's core potential: proactive, close involvement with community development such as that which defined the early twentieth-century educative mission (Buschman 2003; D'Angelo 2006; Usherwood 2007; Hansson 2010). We believe that this shift-promoting the status of information from a means among others to a goal in itself-inhibits new original development and invention in public library services.

\section{The Digital Extension of Library Services}

The concept "digital library" operates on multiple levels in the same fashion that "library" itself is a polysemy. The digital library may refer to an institution, a service, or a type of content (Borgman 1999). An alternative approach is to define it by what it seeks to achieve. The achievement of digital libraries could then be framed as enablement, or empowerment-for example, digital libraries as enablers of knowledge (Candela et al. 2011). This in turn harbors more-specific goal-oriented concepts such as access and sharing. Another field related to digital libraries is that of digital preservation and heritage, focusing on the library as a societal memory institution (Dahlström, Hansson, and Kjellman 2012).

The point-oh suffix is a currently popular device to broadly describe a revolution-like progression of states characterized by big ideas. The dominating library variety thus far has been library 2.0, often in conjunction with the adaptation of library services to social media models and a general shift of content generation and acquisition initiation to patrons (Carlsson 2012). It implicates movement from 1.0, in which the mandate of content and services resided with the library, which catered to passive users. Likewise, it implicates movement toward 3.0, in which user generation takes place in sense-making structures produced by apomediating librarians and realized through semantic technology (Kwanya, Stilwell, and Underwood 2013). Point-oh progression applied to libraries can both describe the library's development as passively tied into larger general schemes and provide ideological fuel for active development. It serves the dual function of both a historical account and a toolbox for change processes.

It could be argued that sensitivity to information and communications technology development is motivated by community engagement (Kwanya et al. 2013), a notion we would support. A critique, however, is that the ideological visions of, for example, library 2.0 in effect 
are subject to the whims of individual, trendsetting major actors such as Facebook, which have owned and authored most of the social media agenda thus far (Carlsson 2012).

From a patron perspective, the division of physical and digital is increasingly blurred and meaningless. This state of fuzziness resonates with Ross Atkinson's seminal notion of "anticollection" (1994). With online resources integrated in its local services, a library can provide access to content outside its core collection in a more or less seamless fashion to the public. The anti-collection is such content, which through mediated access becomes part of a library's offering without technically being part of its collection. The idea of the anti-collection was a relatively early statement of the access-ownership dichotomy embodied by today's libraries (Atkinson 1994). For patrons, the distinction between the local collection, remote access to other libraries' local collections, and access to extralibrary anti-collection is losing its relevance (Van der Veer Martens 2011). In the patrons' view, there probably is no access-ownership dichotomy to begin with (Ross and Sennyey 2008). When a patron reads a printed copy of an electronic scan of an article e-mailed from the remote library where it is physically shelved, these distinctions are reduced to an academic exercise. However, this is not giving license to refrain from studying as something distinct that which is worldly located, corporeal, and discrete. On the contrary, it is vital to explore the unique potential of different materials if they are to contribute relevance to this fuzzy collection climate. To regard the on-site collection as an accessibility-motivated "alternative" to online provision and a reliable archive for preservation is insufficient.

\section{The Strategy of Place}

There is increasing research interest in the library as a place, tangibly in terms of architecture, socially as the "placeness" quality of the situated library. It is also a metaphor for digital libraries - indeed, for the digital library as a place in its own right. A prominent platform for this theme was the aptly named Norwegian project PLACE (CRIStin 2015). In its final publication, the authors anchor the rationale for this strand of research in the need to better understand libraries as contributors to societal goals, in particular pertaining to the local community. They conclude that the library is used as an extension of other places such as home, work, and public places other than the library, resulting in a highly diverse social arena (Aabø and Audunson 2012). Jeffrey Pomerantz and Gary Marchionini similarly argue that libraries are "places that marry physical space with intellectual space, to link people and ideas to each other" $(2007,506)$. Arguably, one of the motivations of this development is a perceived urgency to strengthen the library's purpose and justification, given the prevalence and successes of online information provision (Ross and Sennyey 2008; Robinson 2009). If the library is considered a mere information provider among others, then it is in for some tough competition. So the strategy of place is held forth as integral to libraries and what makes them 
indispensable and unique: "Few community arenas exist with participation from such a variety of the local inhabitants" (Aabø and Audunson 2012, 148).

These notions are important points of departure for our case. Place-oriented research shares our core concern for the public library as a genuine societal hub and impactor, not merely an information provider. As with any particular research focus, numerous factors are inevitably left out, and the place strand of LIS research does highlight two pertinent issues. First is the need for critical inquiry into the potential of progressive invention in physical libraries. In this sense the place perspective is primarily mapping out, explaining, and contextualizing a current state. Second, the singular focus on the library as a social place may not adequately distinguish it, leading to the question of what it is that necessitates the provision of a social place in the particular guise of a public library. For this reason we would complement the place perspective by bringing in the actual content of the on-site library, most obviously its collection. The intuitive approach would perhaps be to talk of services rather than content and on a less specific level than that of collections. However, we argue that the on-site collection offers a suitable extension of the place perspective by adding another dimension to the worldly located, singularly manifested library. Taken together, these different parts constitute the public library's signature offering: a place that lets community members borrow things.

\section{The Drift of Collection Criteria}

Since the mid- and in particular late twentieth century, public library collections have developed in two main dimensions. First, we have seen a radical expansion of the physical collection beyond that of the book (Gardner 1981; Evans and Saponaro 2005). The library collection as physical repository has seen the addition of audiobooks, music, films, video games, and toys. Granted, some materials such as games have been included in collections for much longer; what is new is the expectation that libraries provide them for their increasingly "gaming-literate" patrons (Nicholson 2013). Much collection expansion is in the form of the packaging of digital content as physical records. However, it is still largely the same type of content, centered as it is on the published cultural document, that is, content that (a) from a technical perspective lends itself to description through metadata such as author, title, and publisher and (b) from a social perspective is generally recognized as "culture," adhering to the structures established around the arts. Notable exceptions to this homogeneity include toys, and, less commonly, tools, which we will return to.

The second dimension involves the renegotiation of the library collection as an online resource, in terms of both digitized items and infrastructure. Although both developments run parallel in many respects, they can also be seen as consecutive in terms of paramountcy. The inclusion of new physical media did get under way before the establishment of libraries as 
online actors in any generally acknowledged sense. The library as a routine producer and provider of digital content is realized only in the late twentieth century, if we assume that public Internet connectivity and access are integral to such a realization. Both these dimensions of collection expansion rely heavily on digital copies, so digitality as such is not a dividing factor. It might seem more meaningful to talk about physical and nonphysical dimensions of library collections. However, such a distinction would simplify the issue because in both dimensions the library remains an institution focused on provision. Although provision is certainly crucial to the public library's role in a democratic civic society, it is also an overly onesided focus. We see it exemplified in statements such as "The fundamental role of the library has shifted from warehousing a limited quantity of information to filtering and providing access to the seemingly infinite amount of information available today" (Holden 2010, ix). This tendentious description promotes the information-oriented and passive on-demand view of libraries. By making an arguably derogative warehouse analogy, it demotes the on-site collection to a primitive and inferior precursor to digitized provision. The transformation of the collection as idea in recent decades can be characterized as a drift of criteria. The focus of development has shifted significantly, from collection composition to collection infrastructure, from the content provided to provision itself.

\section{Revitalizing Societal: Collections and Third-Wave Community Engagement Raising the Level of Change}

The alternative to in-depth inquiry into the potential of on-site collections is to assume that physical collections in their present form are completed. This would leave as the only major change factor the incessant struggle over selection/deselection policy and the problematic quality concept (Gardner 1981; Evans and Saponaro 2005). Such change factors are low-level, or internal, compared with critical inquiry into what types of items to stock in a collection to begin with. This level of inquiry lies above discussions of quality, genre, and so forth, which are framed within an already given item type, such as print materials.

It is neither plausible nor desirable to reverse the drift in collection criteria. However, it does need to be tempered by more nuance than is offered by strategies of digital collections and place alone. Ever since Marshall McLuhan (1964) declared more than 50 years ago that "the medium is the message," it has been a common tenet that content and delivery are never fully separable. We support this notion. However, although content and structure are interdependent, it is still perfectly viable to focus more on one than on the other. In this sense, recent development has been lopsided, and the present case is a step toward a more balanced approach in strengthening that which has been neglected: the actual items, or types of items, of the on-site collection. It is relatively straightforward to defend the value of the physical artifact as far as books and other print media are concerned. As argued in a strong case by Robert Bee, the paperbound, possibly multiple editions of a title are never mere vessels. Each instance of a 
particular work is that work, for all intents and purposes. Each manifestation is made meaningful in its worldly context, and on a more concrete note there may be paratext and other design features that are difficult to transfer to other media without distorting the original intent (Bee 2008).

One opening into the object-centric collection is to look at libraries that offer unorthodox materials such as items that are not obviously publication-type documents, that is, items that are not normally considered to be authored and published. These libraries could be divided into two broad categories: the first, public libraries and the second, institutions that are not public libraries but base their operations on a library model. In the former category the most prominent example is probably the toy library, of which there are numerous examples worldwide (Nicholson 2013). Toy libraries are to our knowledge the only nonpublication libraries with their own interest groups and membership associations, organizing themselves nationally and internationally, arranging conferences, and so forth. An example of the latter category is the clothes-lending library. In Sweden, for example, there are a number of clotheslending libraries, ${ }^{2}$ all of which operate as independent nonprofits. Another relevant example that spans both public libraries and library-type operations are tool-lending libraries, the subject of the following sections.

\section{The Services of a Nontraditional On-Site Collection}

The case of tool-lending libraries is interesting for several reasons. First, in casual appreciation, borrowing tools in a library probably seems odd to most of us. It might take a few steps outside our comfort zone to envision a patron swiping his or her card for a chainsaw, to borrow free of charge, and see it properly returned. This very strangeness - tools in libraries makes it excellent fuel for discussion on what library collections can and should be. Second, though tool-lending libraries are common and established enough to provide a case for discussion and study, they are not common or established enough to enjoy widespread recognition. This situation is reflected in academic publishing, which has almost completely overlooked them. On occasion, individual services have been discussed (Benton et al. 1996) without framing the case in any larger library context. In summary, although the first tool-lending library was established in the late 1970s, they are still very much in a state of early development and can be regarded as a phenomenon in the making, not (yet) locked down in fixed notions and structures.

Tool-lending libraries highlight how the issue of collections can be approached on different levels. If we were to compare two traditional publication-centric collections, the comparison would begin at a lower level, where item types are already set. We would examine the

2. Umeå Klädbibliotek (now closed) and Lånegarderoben (http://www.lanegarderoben.com) were the first clotheslending libraries to be established in Sweden, in 2010, and at least three more have opened since. 
distribution in and between subcollections, to gauge, for example, the proportional size of the music section. We could move down through classifications and genres to reach the individual items and evaluate the results of different composition strategies and selection policies. If we were instead to compare a traditional publication-centric collection with a tool collection, a higher level of scrutiny would be required. It would be awkward to compare the proportions of item types. Instead the discussion would need to be moved to item types themselves and the nature of the collection at hand, as it is no longer a given.

The question of how to approach a nontraditional collection is a matter of conflicting standpoints. If we treat the public library as an information resource, the tool-lending library is something of an anomaly. It would be a forced construct to treat tools as if they were information, documents, or media. Technically, tools are of course covered by the popular label "nonprint." With a redefined and expanded collection concept, however, it becomes apparent that such a label is really suitable only for collections that are mainly print-based and where the nonprint materials are still conceptually related to the larger collection. In a collection consisting exclusively or mainly of nonprint items, the label is of little value. If instead we view the public library as a tailored community resource, the idea of lending out tools as a publicly funded city service perhaps starts making more sense.

There is no readily available approach to tools as collection items. Collection development literature does devote particular attention to "other" materials but within the preset boundaries of "media," typically some audiovisual material as opposed to print (Gardner 1981; Evans and Saponaro 2005). A clue might be found in the choice of words such as "media," which hints at a stale nomenclature in need of an update. Collection development theory as such does not dictate valid item types. Rather, we assume that the present state is more a product of the momentum of tradition and normative expectations than of ongoing reflection. Libraries are a fascinating breed of institution in their paradoxical blend of progression and conservatism. They are to be both a springboard into the new world and a hearth of protective calm in its incessant turmoil.

Home repair, gardening, and small-scale "handyman" businesses are among the obvious applications of tool borrowing. Tool-lending libraries showcase how a well-established infrastructure can be repurposed for entirely new types of content. This is arguably the reverse of the general library development trend, where well-established types of content are repurposed for new infrastructures. Tool libraries can employ readily available library systems and routines for cataloging, user registration, lending, and returns. Such integration is evident, for example, in the item posts of the Berkeley Tool Lending Library, fully retrievable in the main library catalog. ${ }^{3}$ 


\section{Empowering the Community through Communalized Collections}

The public library, for all its diverse intentions, is still very much structured around providing readers with books, which is also how both users and nonusers seem to see it (Scott 2011). This in turn is tied in to the notion of the public library as the enabler of equal and equitable access to information (Craven 2011; Feather 2011). We take this as a representation of the unresolved conflict of perspectives mentioned earlier. It is perfectly viable to hold the public library as one of society's most vital cultural institutions, and its frontier to the chaotic realm of information, and its invested hub of the local community. Indeed, it used to be that the public library fulfilled all of these roles in the provision of print matter, and it certainly was not dependent on academic discourse for justification. The role that has perhaps fluctuated the most is that of community engagement. The 1970s was the peak of an expressly outspoken community movement in the guise of local factions and grassroots initiatives, often regarded as radical and not always by mandate of the public library system at large (Black and Muddiman 1997). In opposition have been developments such as consumerism and the influence of "big business" management models, undoubtedly a challenge for community involvement. Alistair Black and Dave Muddiman describe this deterioration as a "post-Fordist flight from ideology" $(1997,10)$. In recent decades, however, there has been renewed interest in community work in Western societies (Scott 2011). In the United States, day-to-day community engagement seems to be relatively thriving, and we see it in Europe as well. Hui-Yun Sung, Mark Hepworth, and Gillian Ragsdell (2013) note an increased awareness and outspoken need of community engagement among UK public libraries. A central notion is diversity, not only with regard to patronage but to staff as well (Jaeger, Bertot, and Subramaniam 2013). This current movement signals a third-wave community engagement, following the first-wave progressive ideologies of the turn of the twentieth century and the second-wave radical notions of the 1970s. These waves are summarized by approximate period and pertinent notion in table 1.

In the wake of first-wave ideology, postmodernity and individualism changed the face of libraries' community involvement, as well as the relationship between communities and pub-

Table 1. Phases of Public Library Community Engagement

\begin{tabular}{lll}
\hline & \multicolumn{1}{c}{ Time Period } & Notions \\
\hline First wave & Early twentieth century & Literacy and public education \\
Second wave & Late 1960s to 1970s & "Radical" grassroots work for targeted* social inclusion \\
Third wave & 2000s to present & Community hubs, open social space, diversity
\end{tabular}

* As opposed to universal, nontargeted library services, which were said to favor those already in favor, that is, the neutrality of public libraries was misguided and so failed to serve the underserved (Black and Muddiman 1997). 
lic libraries (Black and Muddiman 1997). It resulted in an expectation that libraries have everything for everyone. This in turn fosters a passive on-demand approach to provision; a library cannot stock everything and is instead on standby to stock anything. This particular development does not concur with the demand-versus-quality dimension. We would argue that the quality approach still reflects a catchall, or blanket, ideal; quality is simply another kind of demand that applies force of authoritative value judgment rather than force of numbers. The problem from a community perspective is that it results in services that are ideologically concerned with general discussion of what public libraries are supposed to provide rather than with community-specific discussion of what public libraries are supposed to provide. From the perspective of empowering the community, this relationship needs to be rerouted from the local library as a service among others in the library system to the local library as a service among others in the community system. Formally and functionally, a library can of course be both. However, in times of conflict and forced prioritization, which is to say most of the time in the "crisis culture" of public libraries (Buschmann 2003), allegiances need to be set in proper order.

The transformation of public library services is ongoing and is arguably the main target of third-wave community involvement. So far efforts have been focused on redeeming one major aspect of social activity: the social in and of itself. This is largely embodied in developments in social media and in the library as place. It is unfortunate, however, if these developments presuppose an estrangement or a rift between material and social aspects. According to a US library director in Rachel Scott's (2011) study, "Books and materials are really secondary in a library. The most important aspect is the human interaction" (195). Perhaps this type of expression of third-wave ideology is an unintended side effect of a general ambition to steer clear of technological determinism, which leads to an unfortunate downplaying of all materiality and, consequently, collections. Although we agree that materials are not a means to their own end, we take statements such as these as positive provocation suggesting that the relation between collection and community development warrants further investigation.

Communal can be defined as that which is "shared or done by all members of a community" or involves "the sharing of work and property" (Concise Oxford English Dictionary 2008, 289). The derivative communalization, "to communalize," is accordingly the act of making communal. To communalize a collection is to shift ownership - not of collection custody but of collection criteria. It is the social adoption of the on-site collection into its parent community and is thus a step toward bridging the aforementioned rift. "Cultural-sphere-oriented" traditional collections are always a potshot at what the individual community might need. In contrast, a communalized collection is not necessarily nontraditional. The traditional might well be perfectly in tune with the community, which is wholly the point: there is no fixed recipe for success. 


\section{Discussion}

\section{Borrowers or Readers: Who Are Libraries For?}

The many identities of the librarygoer keep stacking up: user, customer, reader, consumer, citizen, community member, borrower, patron. The preferred title will vary by context and over time, and surely we can look forward to new, as yet unheard-of epithets. What is relevant for the present argument is not how people should be categorized but why such an institution should be working with people at all. It could be argued that the provision of print reading matter is increasingly a concern for already well-educated and culturally well-invested members of the middle classes. The state of literacy has indeed changed, but public libraries obviously still have a central role in keeping any gained ground in literacy and promoting its further development. The areas of immediate urgency may have shifted, however, which is a reason to develop the scope of outreach to community members in terms of what the library potentially provides.

For more than a century the public library has engaged in developing its (supposed) field of expertise, from a literacy of literature aimed at supporting social welfare through knowledge, as ultimately embodied in books, to a literacy of information aimed at supporting equitable access, not clearly embodied in anything. This transformation has us constantly trying to fill the gap, which is the public library mission, with meaning. An obvious starting point is the democracy angle. However, to further democracy is arguably a baseline precondition of any public service, not a value-adding option. In the context of a society aspiring to democracy, the distinguishing relevant contribution of public libraries must still be identified. Granted, it may well be that public libraries are particularly suited to be agents of democracy, but the challenge remains to specify how that task is realized not only as a system-level vision but in the individual library in its own particular context.

\section{The Nontraditional Collection and Sustainable Development}

Much younger than the concept of democracy but one that also targets life-and-death issues in pursuit of a better world is the concept of sustainable development, or sustainability. Like its Greek ancestor, it is a big idea, vast in scope, grand in vision, and bristling with urgency. Similarly, it is also constantly contested: What exactly is sustainability? And, even more divisive: How do we achieve it? It has been justly called an "epistemic monster" (Jeanneret 2008), and its conceptual flexibility means it can apply to almost any context without any real change having to be made (Nolin 2010). Stakeholders do not have to adapt to sustainability when sustainability can be adapted to them, following the path of least resistance-and quickest payoff. It also involves the difficult transition from abstract scientific knowledge to the complex real world, and vice versa. Bernd Klauer, Reiner Manstetten, Thomas Petersen, and Johannes Schiller discuss how this may motivate a pessimist position, holding that "political decisions and policy 
recommendations based on science are either arbitrary or else determined by narrow interests" $(2013,80)$. For any particular stance in a complex issue, there is likely to be research that can be said to support that stance. Stakeholders can make up their minds and then turn to research to complement their case with scholarly backup, in that order. However, librarians and library researchers should take this as a positive provocation to actively engage in forceful discussion, development, and application of sustainability ideas. As with democracy, there is little hope that a ready-made solution will be provided by committee. Rather, big systems of ideas depend on constant reproduction where being in flux is the normal state. A fixed, uncontested format could only be achieved under dictatorship-like conditions.

The lending-borrowing system hosted by public libraries seems to relate to sustainable development on an immediate community level. A starting point is to treat borrowing as a consumption issue, basically as an available mode of acquisition among others. We intentionally choose not to frame borrowing as "alternative," that is, as in "an alternative to consumption." Although we have not traced the lineage of borrowing, we are fairly confident in calling it a wellestablished practice. There is nothing obvious to suggest it is something new or innovative compared with buying, for instance. Moreover, "alternative" assumes that the act of borrowing is undertaken in intentional contrast to some other, supposedly normal conduct. We could easily imagine the reverse, at least in the case of libraries: the habitual book borrower discovers that every copy is lent out and that there is a waiting list so instead resorts to an alternative strategy and buys the book. Finally, we do not wish to isolate borrowing from the idea of consumption but rather to explore how they are related. We believe a "good versus bad" separation of borrowing from consumption to be both presumptuous and overly simplistic. Taken together, these premises allow for discussion on the role of public libraries in consumption-presently and potentially.

Borrowing can thus be conceptualized as a component of everyday consumption strategies and as related to the complex social, economic, and ecological structure of sustainable development. Tool-lending libraries, for example, might offer several hands-on examples of these forces at play, such as supporting individuals in becoming self-employed in heavily tooldependent businesses. Helping community members overcome unemployment has obvious social and economic dimensions, as well as environmental aspects regarding dependence on manufactured items. Furthermore, it is not only a matter of borrowing as such but also of what is being borrowed. For example, utility monitoring equipment may be lent out as part of energyefficiency programs (Benton et al. 1996). It is tempting to propose an all-out correlation between borrowing and positive sustainability impact, and we are of course partial to the potential of public library services. However, sustainable development is foremost a complex system of high-level ideas, sorely lacking in consensus when it comes to specification, implementation, and evaluation. Thus, it would be presumptuous to ascribe any particular causality to borrowing with regard to sustainability impact. At this point it is rather a matter 
of identifying tangential aspects. Borrowing, when compared to other means of acquisition, promotes discussion of community sustainability issues such as social inclusion, various brands of literacy, household sustenance, and local business - in sum, empowerment of its members.

\section{The On-Site Collection and the Rejuvenation of Public Library Space}

This article has focused on the public library in its reiteration as a worldly located social space. It is a place built around a collection and a collection built around a place, an ongoing process most clearly embodied by the neighborhood branch library. This process is one that is potentially owned by the community it is serving as much as, or more than, any larger system, policy, or ideology. In the face of wholesale globalization, the local public library is immensely important, not merely as an intermediary or apomediary to some outer world but even more so in looking inward toward the small world to which it is integral. Such a perspective enables genuine invention, possibly to the detriment of tradition and confounding in the eyes of outside spectators. Public library "anomalies" such as tool-lending libraries likely demand a particular brand of skill sets from their staff, perhaps not more specialized but differently specialized compared to traditional librarianship. Arts studies may not be generally mandatory in LIS education and likewise not generally required for positions. At the same time, subjects such as literature are still obviously related to LIS on other levels, if not formally then traditionally and thematically in what libraries and librarians are about. Thus, it is not simply a matter of stuffing libraries with new things and otherwise carrying on as usual. This is what we mean by "genuine invention": a requirement to produce new ideas regarding library collections on all levels of development, not just in professional practice but also in our subject curricula and, as we are attempting here, research.

The social place and space of public libraries needs be investigated as more than a confluence of people in a material vacuum. Otherwise their distinction and relation to other socially oriented community institutions becomes unclear. A public library site without a collection would be a dubious library indeed; the two cannot be properly separated in any meaningful way. It is therefore vital that the resident collection is seen as part of the library place and that discussion of the social space of libraries is inclusive of collections. The idea of a library offering a nontraditional collection effectively forces such considerations if we also want to avoid an "anything goes" approach. The idea of tool-lending libraries makes sense not because it is a template for all future library services but rather the opposite. The tool-lending library is an illustration of sense made on the local level; to copy it as an off-the-shelf solution would not necessarily work. The kinds of services that are perfectly relevant to one community might well fail in another. The perceived need and incentive to borrow tools, for example, is probably due to a number of factors. Tangibles such as housing and income distribution, as well as intangibles such as lifestyle ideology and overall attitude toward public 
services, all surely play a part. The community collection is the manifested concern of the people belonging to a particular place at a particular time.

\section{References}

Aabø, Svanhild, and Ragnar Audunson. 2012. "Use of Library Space and the Library as Place." Library and Information Science Research 34 (2): 138-49.

American Library Association. 1996. Library Bill of Rights. http://www.ala.org/advocacy/intfreedom /librarybill.

Atkinson, Ross. 1994. "Access, Ownership, and the Future of Collection Development." In Collection Management and Development: Issues in an Electronic Era: Proceedings of the Advanced Collection Management and Development Institute, Chicago, Illinois, March 26-28, 1993, edited by Peggy Johnson and Bonnie MacEwan. Chicago: American Library Association.

Audunson, Ragnar. 2005. "The Public Library as a Meeting-Place in a Multicultural and Digital Context: The Necessity of Low-Intensive Meeting-Places.” Journal of Documentation 61 (3): 429-41.

Bee, Robert. 2008. “The Importance of Preserving Paper-Based Artifacts in a Digital Age.” Library Quarterly 78 (2): 179-94.

Bell, Daniel. 1973. The Coming of Post-Industrial Society: A Venture in Social Forecasting. New York: Basic Books.

Benton, Charles C., Charlie Huizenga, Robert Marcial, Mark Hydeman, and Jim Chase. 1996. "Taking a Building's Vital Signs: A Lending Library of Handheld Instruments." In Proceedings from the 1996 and 1994 ACEE Summer Studies on Energy Efficiency in Buildings. Vol. 4. Washington, DC: American Council for an Energy-Efficient Economy.

Black, Alistair, and Dave Muddiman. 1997. Understanding Community Librarianship: The Public Library in PostModern Britain. Aldershot, UK: Avebury.

Borgman, Christine L. 1999. "What Are Digital Libraries? Competing Visions.” Information Processing and Management 35 (3): 227-43.

British Library Board. 2010. 2020 Vision. London: British Library.

Buschman, John. 2003. Dismantling the Public Sphere: Situating and Sustaining Librarianship in the Age of the New Public Philosophy. Westport, CT: Libraries Unlimited.

Candela, Leonardo, Donatella Castelli, and Pasquale Pagano. 2011. "History, Evolution and Impact of Digital Libraries." In E-Publishing and Digital Libraries: Legal and Organizational Issues, edited by Tatiana-Eleni Synodinou, Sarantos Kapidakis, and Ioannis Iglezakis. Hershey, PA: IGI Global.

Carlsson, Hanna. 2012. "Working with Facebook in Public Libraries: A Backstage Glimpse into the Library 2.0 Rhetoric." Libri 62 (3): 199-303.

Concise Oxford English Dictionary. 2008. Edited by Catherine Soanes and Angus Stevenson. Oxford: Oxford University Press.

Craven, Jenny. 2011. "Widening Access to Information: The Haves and the Have-Nots?" In Libraries and Society: Role, Responsibility and Future in an Age of Change, edited by David Baker and Wendy Evans. Oxford: Chandos.

CRIStin (Current Research Information System in Norway). 2015. PLACE: Public Libraries—Arenas for Citizenship: An Investigation of the Public Library as a Meeting Place in a Digital and Multicultural Context. https:// www.cristin.no/app/projects/show.jsf?id=288092. 
Dahlström, Mats, Joacim Hansson, and Ulrika Kjellman. 2012. “'As We May Digitize': Institutions and Documents Reconfigured." LIBER Quarterly 21 (3/4): 455-74.

D'Angelo, Edward. 2006. Barbarians at the Gates of the Public Library: How Postmodern Consumer Capitalism Threatens Democracy, Civil Education and the Public Good. Duluth, MN: Library Juice.

Evans, G. Edward, and Margaret Zarnosky Saponaro. 2005. Developing Library and Information Center Collec tions. Westport, CT: Libraries Unlimited.

Feather, John. 2011. "Free and Equal Access: A Conundrum for the Information Society." In Libraries and Society: Role, Responsibility and Future in an Age of Change, edited by David Baker and Wendy Evans. Oxford: Chandos.

Gardner, Richard K. 1981. Library Collections: Their Origin, Selection and Development. New York: McGraw-Hill.

Goulding, Anne. 2009. "Engaging with Community Engagement: Public Libraries and Citizen Involvement." New Library World 110 (1/2): 37-51.

Hansson, Joacim. 2010. Libraries and Identity: The Role of Institutional Self-Image and Identity in the Emergence of New Types of Libraries. Oxford: Chandos.

Harris, Michael H. 1999. History of Libraries in the Western World. Lanham, MD: Scarecrow.

Harris, Michael H., Stan A. Hannah, and Pamela C. Harris. 1998. Into the Future: The Foundations of Library and Information Services in the Post-Industrial Era. Greenwich, CT: Ablex.

Holden, Jesse. 2010. Acquisitions in the New Information Universe: Core Competencies and Ethical Practices. London: Facet Publishing.

Jaeger, Paul T., John Carlo Bertot, and Mega Subramaniam. 2013. "Preparing Future Librarians to Effectively Serve Their Communities." Library Quarterly 83 (3): 243-48.

Jeanneret, Yves. 2008. "The Epistemic Jumble of Sustainable Development.” In Communicating Science in Social Contexts: New Models, New Practices, edited by Donghong Cheng. New York: Springer.

Johannesson, Krister. 2009. "I främsta rummet: Planerandet av en högskolebiblioteksbyggnad med studenters arbete i fokus" [In the foremost room: Planning a university library building with a focus on student work]. PhD diss., University of Borås.

Klauer, Bernd, Reiner Manstetten, Thomas Petersen, and Johannes Schiller. 2013. "The Art of Long-Term Thinking: A Bridge between Sustainability Science and Politics." Ecological Economics 93:79-84.

Koerin, Beverly. 2003. "The Settlement House Tradition: Current Trends and Future Concerns." Journal of Sociology and Social Welfare 30 (2): 53-68.

Kwanya, Tom, Christine Stilwell, and Peter G. Underwood. 2013. "Intelligent Libraries and Apomediators: Distinguishing between Library 3.0 and Library 2.0." Journal of Librarianship and Information Science 45 (3): $187-97$.

Lerner, Frederick Andrew. 2009. The Story of Libraries: From the Invention of Writing to the Computer Age. London: Continuum.

McLuhan, Marshall. 1964. Understanding Media: The Extensions of Man. London: Routledge.

Nicholson, Scott. 2013. "Playing in the Past: A History of Games, Toys, and Puzzles in North American Libraries." Library Quarterly 83 (4): 341-61.

Nixon, Judith M., Robert S. Freeman, and Suzanne M. Ward. 2010. "Patron-Driven Acquisitions: An Introduction and Literature Review." Collection Management 35 (3/4): 119-24.

Nolin, Jan. 2010. "Sustainable Information and Information Science." Information Research 15 (2): paper 431. Pomerantz, Jeffrey, and Gary Marchionini. 2007. "The Digital Library as Place." Journal of Documentation 63 (4): 505-33. 
Robinson, Cynthia K. 2009. "Library Space in the Digital Age: The Pressure Is On." Bottom Line: Managing Library Finances $22(1): 5-8$.

Ross, Lyman, and Pongracz Sennyey. 2008. "The Library Is Dead, Long Live the Library! The Practice of Academic Librarianship and the Digital Revolution." Journal of Academic Librarianship 34 (2): 145-52.

Scott, Rachel. 2011. "The Role of Public Libraries in Community Building." Public Library Quarterly 30 (3): $191-227$.

Skot-Hansen, Dorte, Casper Hvenegaard Rasmussen, and Henrik Jochumsen. 2013. "The Role of Public Libraries in Culture-Led Urban Regeneration." New Library World 114 (1/2): 7-19.

Sung, Hui-Yun, Mark Hepworth, and Gillian Ragsdell. 2013. "Investigating Essential Elements of Community Engagement in Public Libraries: An Exploratory Qualitative Study." Journal of Librarianship and Information Science 45 (3): 206-18.

Usherwood, Bob. 2007. Equity and Excellence in the Public Library: Why Ignorance Is Not Our Heritage. Aldershot, UK: Ashgate.

Van der Veer Martens, Betsy. 2011. "Approaching the Anti-Collection.” Library Trends 59 (4): 568-87.

Webster, Frank. 2006. Theories of the Information Society. London: Routledge.

Yan, Miu Chung, and Rick Sin. 2011. "The Resilience of the Settlement-House Tradition in Community Development: A Study of Neighborhood Centers in San Francisco.” Community Development 42 (1): 106-24.

Jonas Söderholm: doctoral candidate at the Swedish School of Library and Information Science, joint program of University of Borås and University of Gothenburg. A former design consultant and editor for academic, public, and private clients, he now mainly teaches within the university's library program. His PhD project investigates public libraries as resources for community members' borrowing. This includes an interest in nontraditional collections, local sustainable development, community building, and mixed-methods research. Söderholm also is currently editor of the scholarly journal Human IT and a member of the university Sustainability Council. E-mail: jonas .soderholm@hb.se.

Jan Nolin: professor of library and information science at the Swedish School of Library and Information Science, University of Borås. Nolin completed his PhD in theory of science in 1995. His current research focuses on renegotiation of library practices in the context of emerging information technology. Additional research interests concern theory of professions, social media studies, the Internet of things, big data, and the integration of the values of sustainable development within library and information science. E-mail: jan.nolin@hb.se. 